\title{
SISTEM INFORMASI MANAJEMEN RUMAH SUSUN SUMBAWA UNIVERSITAS TEKNOLOGI SUMBAWA BERBASIS WEB
}

\author{
Yana Karisma $^{1}$, M. Julkarnain ${ }^{2}$, Shinta Esabella ${ }^{3 *}$, Muhammad Rifqi Fawzan ${ }^{4}$ \\ 1,2,3,4 Teknik Informatika, Universitas Teknologi Sumbawa \\ email: shinta.esabella@uts.ac.id**
}

\begin{abstract}
Abstrak: Penelitian ini bertujuan untuk membuat Sistem Informasi Manajemen Rumah Susun Sumbawa Universitas Teknologi Sumbawa Berbasis Web agar dapat dimanfaatkan oleh Pengurus Rumah Susun Sumbawa (RUSUNAWA) Universitas Teknologi Sumbawa. Adapun metode yang digunakan dalam penelitian ini yaitu metode kualitatif dan metode pengumpulan data yang digunakan dalam penelitian ini yaitu wawancara, observasi, dan studi literatur dan juga menggunakan Waterfall Methode sebagai metode pengembangan perangkat lunak. Sistem Informasi Manajemen Rumah Susun Sumbawa Universitas Teknologi Sumbawa Berbasis Web dibuat menggunakan bahasa pemrograman PHP dan basis data MySQL sebagai database. Dengan adanya Sistem Informasi ini diharapkan mempermudah pengurus Rumah Susun Sumbawa dalam melakukan pendataan dan manajemen seluruh kegiatan yang ada di Rumah Susun Sumbawa.
\end{abstract}

Kata Kunci: Sistem Informasi, Manajemen, Berbasis Web, Waterfall Methode

Abstract: This study aims to create a Web-based Sumbawa Flats Management Information System, Sumbawa University of Technology, so it can be used by the Sumbawa Flats Management (RUSUNAWA) Sumbawa Technology University. The methods used in this study are qualitative methods and data collection methods used in this study, namely interviews, observations, and literature studies and using the Waterfall Method as a software development method. The Web-Based Management Information System of Sumbawa Flats, Sumbawa University of Technology, was created using the PHP programming language and MySQL as the database. With this information system, it is hoped that it will make it easier for Sumbawa Flats to collect data and manage all activities in Sumbawa Flats.

Keywords: Information Systems, Management, Web-Based, Waterfall Method

\section{PENDAHULUAN}

Universitas Teknologi Sumbawa (UTS) merupakan sebuah perguruan tinggi yang terletak di Pulau Sumbawa Provinsi Nusa Tenggara Barat, setiap tahunnya Universitas Teknologi Sumbawa membuka beasiswa untuk mahasiswa baru dari luar daerah. Tidak heran jika Universitas Teknologi Sumbawa diminati oleh para masyarakat, karena memiliki keanekaragaman budaya dari mahasiswanya sendiri.

Di UTS sampai dengan saat ini menyediakan tempat tinggal untuk mahasiswa baru yang berbeasiswa, dimana lokasinya tidak jauh dari kampus dan dapat ditempuh dalam waktu kurang lebih 10 menit dengan berjalan kaki dari asrama menuju kampus. Tempat tinggal yang disediakan oleh UTS biasa disebut Rumah Susun Sumbawa (RUSUNAWA) yang memiliki dua buah gedung dengan masing - masing empat tingkat.

Pada awal kedatangan para mahasiswa baru yang berbeasiswa ditempatkan di asrama RUSUNAWA supaya mudah didata dan melakukan perkenalan dengan pembina dan pengurus asrama RUSUNAWA serta berkenalan dengan para penghuni yang lainnya. Asrama RUSUNAWA memiliki kegiatan sehari - hari untuk para penghuninya yang sudah ditentukan oleh pembina asrama dan tata tertib untuk seluruh penghuni RUSUNAWA. Ada beberapa penghuni asrama yang tidak mengetahui tata tertib asrama serta kegiatan kegiatan yang ada di asrama RUSUNAWA, sehingga para pengurus asrama harus memanggil para penghuni asrama dengan menuju kamar satu persatu, tentunya hal ini sangat tidak efisien dikarenakan kurang dalam mengelola informasi yang akan diberitahukan kepada para penghuni asrama RUSUNAWA.

Dalam masalah mengelola asrama RUSUNAWA, pembina atau pengurus harus mendata semua penghuni asrama yang ada serta menginformasikan semua kegiatan dan tata tertib yang harus di taati, para penghuni asrama harus dipisah dalam penempatan kamar tidur dengan minimal 3 orang dari daerah yang berbeda, semua masih di lakukan dengan manual, tentunya ini membutuhkan waktu yang lama dan tidak efektif dalam mengelola data dikarenakan data yang tersimpan dapat hilang sewaktu - waktu dan ini akan sangat menyulitkan untuk pembina dan pengurus asrama ketika penghuni asrama yang bersangkutan terjadi hal yang tidak diinginkan selama tinggal di asrama RUSUNAWA Universitas Teknologi Sumbawa. Dalam mengelola izin yang ada di asrama RUSUNAWA Pembina dan pengurus asrama sedikit menerima informasi para penghuni asrama yang izin keluar atau masuk asrama karena masih dilakukan pendataan secara manual dengan buku, tentunya hal ini membutuhkan waktu yang lama dan tidak efektif.

Berdasarkan permasalahan yang ada, peneliti membangun sebuah sistem untuk manajemen RUSUNAWA Universitas Teknologi Sumbawa. Sistem ini nantinya akan dipakai oleh semua penghuni asrama RUSUNAWA, terutama untuk pembina dan pengurus dalam mengolah data penghuni asrama, data perizinan, serta informasi kegiatan yang ada.

Dengan adanya sistem ini, diharapkan dapat menjadi solusi dalam memudahkan pembina dan 
pengurus asrama RUSUNAWA untuk mengawasi, menertibkan, memberitahukan, dan mengolah data yang ada, sehingga dalam semua kegiatan yang ada dapat berjalan dengan efektif dan efisien serta dapat menyampaikan informasi dengan tepat waktu.

\section{TINJAUAN PUSTAKA}

Peneliti menemukan beberapa penelitian yang mempunyai keterkaitan dengan penelitian yang peneliti lakukan.

Penelitian pertama yang mempunyai keterkaitan dengan penelitian yang peneliti lakukan adalah penelitian dari Khusniatul Fahriya dan Andi Iwan Nurhidayat (2018) dengan judul "Rancang Bangun SIMAWA (Sistem Informasi RUSUNAWA) Berbasis Web Application Menggunakan Framework Laravel (Studi Kasus : Universitas Negeri Surabaya)". Masalah penelitian ini adalah kurangnya informasi terkait RUSUNAWA yang mengakibatkan para penghuni harus mendatangi pengelola untuk melakukan pendaftaran serta pengolahan data yang masih manual. Tujuan dari penelitian ini adalah untuk mempermudah proses pengolahan data dengan cepat, tepat, akurat, dan efisien serta mempermudah penghuni dalam melakukan pendaftaran. Metode pengembangan perangkat lunak yang digunakan adalah Prototype Methode.

Hasil penelitian menunjukan sistem berjalan dengan semestinya dimana penghuni dapat melakukan pendaftaran dan pengunduran dengan mudah serta memudahkan pengelola dalam manajemen data - data para penghuni.

Kemudian penelitian kedua yang peneliti temukan adalah penelitian dari Teuku Mufizar, Cepi Rahmat Hidayat, dan Wahyu Kamaludin (2018) dengan judul "Sistem Informasi Terintegrasi Untuk Pengelolaan Rusunawa STMIK Tasikmalaya". Masalah penelitian ini adalah pengelola Rusunawa STMIK Tasikmalaya masih dilakukan secara manual dan belum memiliki sistem informasi berbasis komputer, proses pendataan penghuni, pendataan pengunjung, pembayaran sewa, dan inventarisir barang masih menggunakan teknik pencatatan pada buku atau formulir dan dilakukan secara terpisah pisah di masing - masing bagian. Tujuan dari penelitian ini adalah mempurmudah dalam pengelolaan data yang ada di Rusunawa STMIK Tasikmalaya. Metode pengembangan sistem yang digunakan dalam penelitian ini adalah SDLC (System Development Life Cycle) dengan Waterfall Methode.

Hasil penelitian menunjukan aplikasi berjalan dengan dengan baik dimana data menjadi terpusat pada basis data yang dapat diakses oleh semua unit kerja yang ada di Rusunawa STMIK Tasikmalaya dan mempermudah dalam pengelolaan data.

Demikian hasil observasi yang peneliti temukan dimana terdapat judul serta permasalahan yang mempunyai kesamaan dengan penelitian yang dilakukan peneliti walaupun demikian dalam penelitian yang peneliti lakukan terdapat perbedaan mulai dari lokasi penelitian, pengelolaan data, serta fitur - fitur yang ada seperti tata tertib, informasi kegiatan, perizinan, dan informasi penghuni.

Adapun penelitian yang peneliti lakukan adalah penelitian dengan judul "Sistem Informasi Manajemen Rumah Susun Sumbawa Universitas Teknologi Sumbawa Berbasis Web". Masalah yang terjadi pada penelitian ini adalah pengelolaan data yang masih secara manual serta informasi yang harus disampaikan dengan pemberitahuan kepada pengurus. Tujuan dari penelitian ini adalah membuat sebuah sistem untuk mengelola data yang ada di RUSUNAWA agar lebih efisien. Metode pengumpulan data yang digunakan adalah Waterfall Methode.

\section{Rancang Bangun}

Rancang merupakan serangkaian prosedur untuk menerjemahkan hasil analisa dari sebuah sistem ke dalam bahasa pemrograman untuk mendeskripsikan dengan detail bagaimana komponen-komponen sistem diimplementasikan (Pressman, 2002). Rancangan sistem adalah penentuan proses dan data yang diperlukan oleh sistem baru. Perancangan adalah kegiatan yang memiliki tujuan untuk mendesain sistem baru yang dapat menyelesaikan masalah-masalah yang dihadapi perusahaan yang diperoleh dari pemilihan alternatif sistem yang terbaik. Sedangkan pengertian bangun atau pembangunan sistem adalah kegiatan menciptakan sistem baru maupun mengganti atau memperbaiki sistem yang telah ada baik secara keseluruhan maupun sebagian (Pressman, 2002).

Bangun sistem adalah membangun sistem informasi dan komponen yang didasarkan pada spesifikasi desain. Rancang bangun merupakan kegiatan menerjemahkan hasil analisa ke dalam bentuk paket perangkat lunak kemudian menciptakan sistem tersebut ataupun memperbaiki sistem yang sudah ada. (Nuri \& Yulia, 2015).

\section{Sistem}

Sistem didefinisikan menjadi "suatu sistem adalah suatu jaringan kerja dari prosedur - prosedur yang saling berhubungan, berkumpul bersama - sama untuk melakukan suatu kegiatan atau untuk menyelesaikan suatu sasaran tertentu. (Jogiyanto HM, 1999: 1).

\section{Informasi}

Informasi dapat didefinisikan sebagai hasil dari pengolahan data dalam suatu bentuk yang lebih berguna dan lebih berarti bagi penerimanya yang menggambarkan suatu kejadian - kejadian (event) yang nyata (fact) yang digunakan untuk pengambilan keputusan. (Jogiyanto HM, 1999: 692).

\section{Sistem Informasi}

Sistem informasi adalah suatu sistem terintegrasi yang mampu menyediakan informasi yang bermanfaat bagi penggunanya atau sebuah sistem terintegrasi untuk menyediakan informasi yang 
bertujuan mendukung operasi dan manajemen dalam suatu organisasi. Sistem ini memanfaatkan perangkat keras dan perangkat lunak komputer, prosedur manual, model manajemen, serta basis data (Alfarisyi \& Amila, 2014).

\section{Sistem Informasi Manajemen}

Sistem informasi manajemen merupakan sistem yang mengolah serta mengorganisasikan data dan informasi yang berguna untuk mendukung pelaksanaan tugas dalam suatu organisasi (Slamet Hariyanto, 2016).

\section{Rumah Susun}

Rumah susun adalah bangunan gedung bertingkat yang dibangun dalam suatu lingkungan yang terbagi dalam bagian - bagian yang distrukturkan secara fungsional dalam arah horizontal maupun vertical dan merupakan satuan - satuan yang masing masing dapat dimiliki dan digunakan secara terpisah, terutama untuk tempat hunian yang dilengkapi dengan bagian bersama, benda bersama, dan tanah bersama (Kartika \& Edward, 2012).

\section{Flowchart}

Bagan alir flowchart adalah bagan chart yang enunjukkan alir flow di dalam program atau prosedur sistem secara logika (Jogiyanto, 2005). Bagan alir program (Program flowchart) merupakan bagan alir yang mirip dengan bagan alir sistem, yaitu untuk menggambarkan prosedur di dalam sistem. (Jogiyanto, 2005).

\section{Unified Modelling Language (UML)}

Unified Modelling Language (UML) adalah suatu alat untuk memvisualisasikan dan mendokumentasikan hasil analisa dan desain yang berisi sintak dalam memodelkan sistem secara visual. Juga merupakan satu kumpulan konvensi pemodelan yang digunakan untuk menentukan atau menggambarkan sebuah sistem software yang terkait dengan objek (M. Ropianto, 2016).

\section{Waterfall}

Model waterfall adalah model pengembangan perangkat lunak yang paling sering digunakan. Model pengembangan ini bersifat linear dari tahap awal pengembangan sistem yaitu tahap perencanaan sampai tahap akhir pengembangan sistem yaitu tahap pemeliharaan (Rani \& Anna, 2010).

\section{XАMPP}

XAMPP adalah perangkat lunak bebas yang mendukung banyak sistem operasi, merupakan kompilasi dari beberapa program. Fungsinya adalah sebagai server yang berdiri sendiri (localhost) yang terdiri atas program Apache HTTP Server, MySQL database, dan penerjemah bahasa yang ditulis dengan bahasa pemrograman PHP (Hypertext Preprocessor) dan Perl (Dwi \& Siska, 2013).
MySQL

$M y S Q L$ sebenarnya merupakan turunan salah satu konsep utama dalam basis data yang telah ada sebelumnya, SQL (Structure Query Language). SQL adalah sebuah konsper pengoperasian basis data, terutama untuk pemilihan atau seleksi dan pemasukan data yang memungkinkan pengoperasian data dikerjakan dengan mudah secara otomatis (Dwi \& Siska. 2013).

\section{METODE}

Metodologi pada penelitian ini yaitu sebagai berikut :

\section{Metode penelitian}

Metode penelitian yang digunakan dalam melakukan penelitian ini peneliti menggunakan dua metode, yaitu metode pengumpulan data dan metode pengembangan perangkat lunak.

\section{Metode Pengembangan Perangkat Lunak}

Metode pengembangan perangkat lunak yang digunakan dalam penelitian "Sistem Informasi Manajemen Rumah Susun Sumbawa Universitas Teknologi Sumbawa Berbasis Web" adalah Waterfall Methode. Berikut ini tahapan - tahapan dalam pengembangan perangkat lunak dalam penelitian:

\section{a. Requirements (Analisis)}

Pada tahap ini peneliti melakukan analisis untuk mendapatkan data yang dibutuhkan dalam penelitian ini, di sini peneliti melakukan beberapa tahapan untuk mendapatkan data yang dibutuhkan, yaitu :

1. Peneliti melakukan wawancara kepada Bapak Iwan Wahyudi, SE., selaku pembina asrama untuk mendapatkan beberapa data yang dibutuhkan dalam penelitian.

2. Peneliti melakukan observasi langsung ke lapangan tempat penelitian akan dilakukan untuk mengidentifikasi batasan masalah dalam penelitian yang akan dibuat peneliti.

3. Peneliti melakukan studi literatur untuk mencari dan mempelajari pustaka yang ada sebagai bahan acuan dan pertimbangan dalam penelitian yang diperoleh dari jurnal, skripsi, dan buku.

\section{b. Design (Perancangan)}

Pada tahap ini peneliti melakukan rancangan awal dari sebuah sistem, fitur apa saja yang akan disediakan oleh sistem, serta membuat rancangan user interface yang nantinya akan dipakai oleh sistem.

\section{c. Implementation}

Pada tahap ini peneliti akan mulai membuat sistem dengan melakukan pengkodean yang sesuai dengan perancangan user interface yang sudah dilakukan pada tahap desain. 
d. Verification (Pengujian)

Pada tahap ini peneliti akan melakukan testing sistem, apakah sudah berjalan dengan semesatinya atau tidak, di sini juga peneliti akan melakukan uji coba sistem dari semua fitur - fitur yang tersedia di sistem.

\section{e. Maintenance (Perbaikan)}

Pada tahap ini peneliti akan melakukan perbaikan terhadap sistem yang sudah berjalan dan melakukan pemeliharaan terhadap sistem supaya tidak terjadi error.

\section{Flowmap yang Berjalan}

Analisis sistem yang sedang berjalan pada pengolahan data penghuni sebagai berikut:

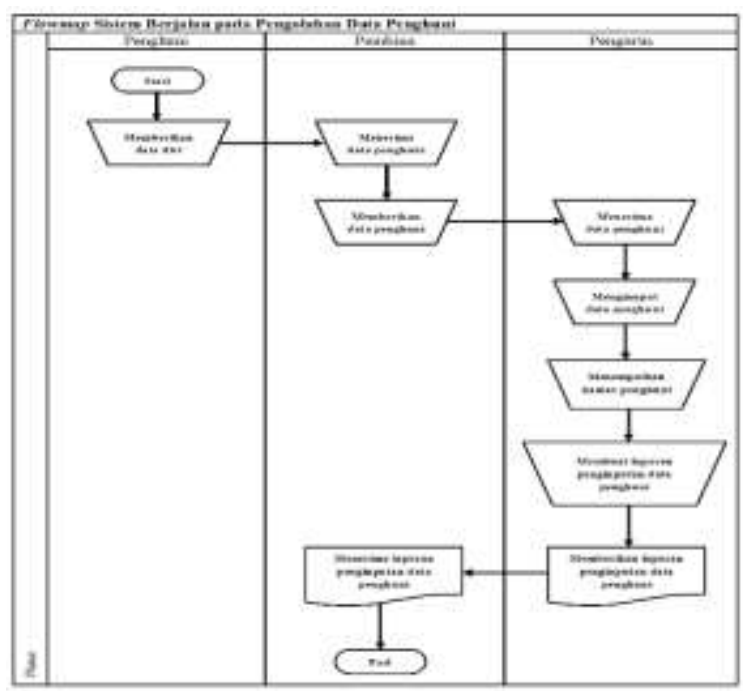

Gambar 1. Flowmap Sistem Berjalan Pada Pengolahan Data Penghuni

\section{Flowmap yang Diusulkan}

: Analisis sistem usulan yang peneliti usulkan untuk pengolahan data penghuni sebagai berikut :

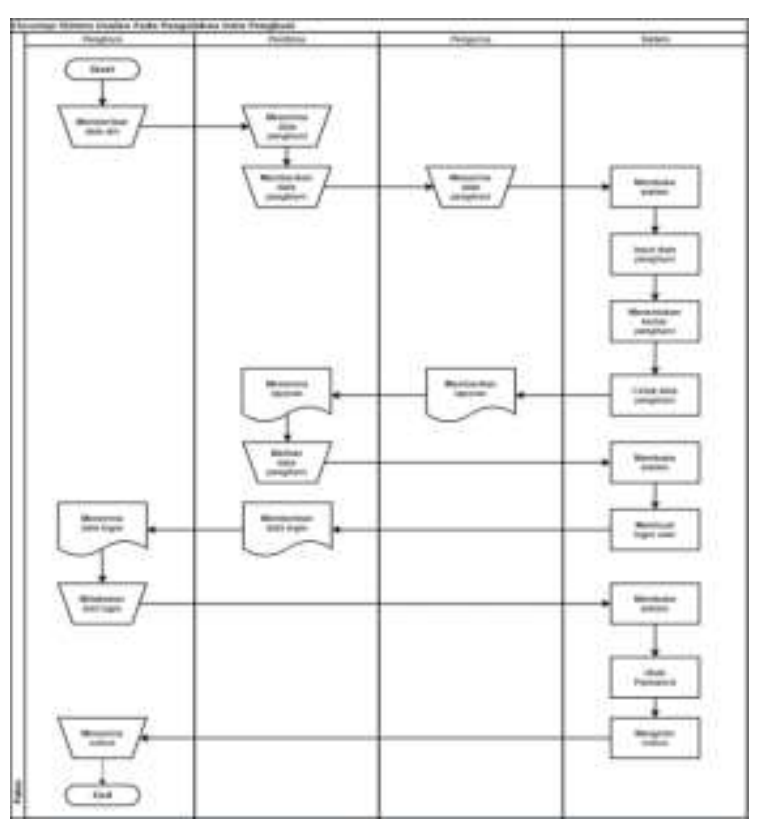

Gambar 2. Flowmap Sistem Usulan

\section{Perangkat Pengguna Sistem}

Perangkat pengguna sistem yaitu perangkat keras dan perangkat lunak yang dapat dilihat pada tabel di bawah ini :

Tabel 1. Perangkat Pengguna Sistem

\begin{tabular}{|c|l|}
\hline Perangkat & Spesifikasi \\
\hline Perangkat & Laptop: \\
Keras & a. Processor Intel $®$ Core $^{\mathrm{TM}}$ i7- \\
& \multicolumn{1}{|c|}{$7500 U$ CPU @ 2.5 Ghz 3.5 Ghz } \\
& b. Ram 8.00 GB DDR3 \\
& c. Harddisk: 1 TB \\
\hline Perangkat & - Sistem Operasi: Windows 10 \\
Lunak & - Tools: \\
& a) XAMPP \\
& b) Dreamweaver CS6 \\
& - Database: MySQL \\
\hline
\end{tabular}

\section{HASIL DAN PEMBAHASAN}

Hasil dan pembahasan pada penelitian ini dapat diuraikan sebagai berikut :

\section{Use Case Diagram}

Pada bagian use case diagram dibagi menjadi tiga bagian, yaitu use case diagram pembina, use case diagram pengurus, dan use case diagram penghuni. Berikut ini adalah use case diagram pada Sistem Informasi Manajemen Rumah Susun Sumbawa Universitas Teknologi Sumbawa Berbasis Web adalah sebagai berikut :

\section{Use Case Diagram Pembina}

Adapun desain use case diagram Pembina adalah sebagai berikut :

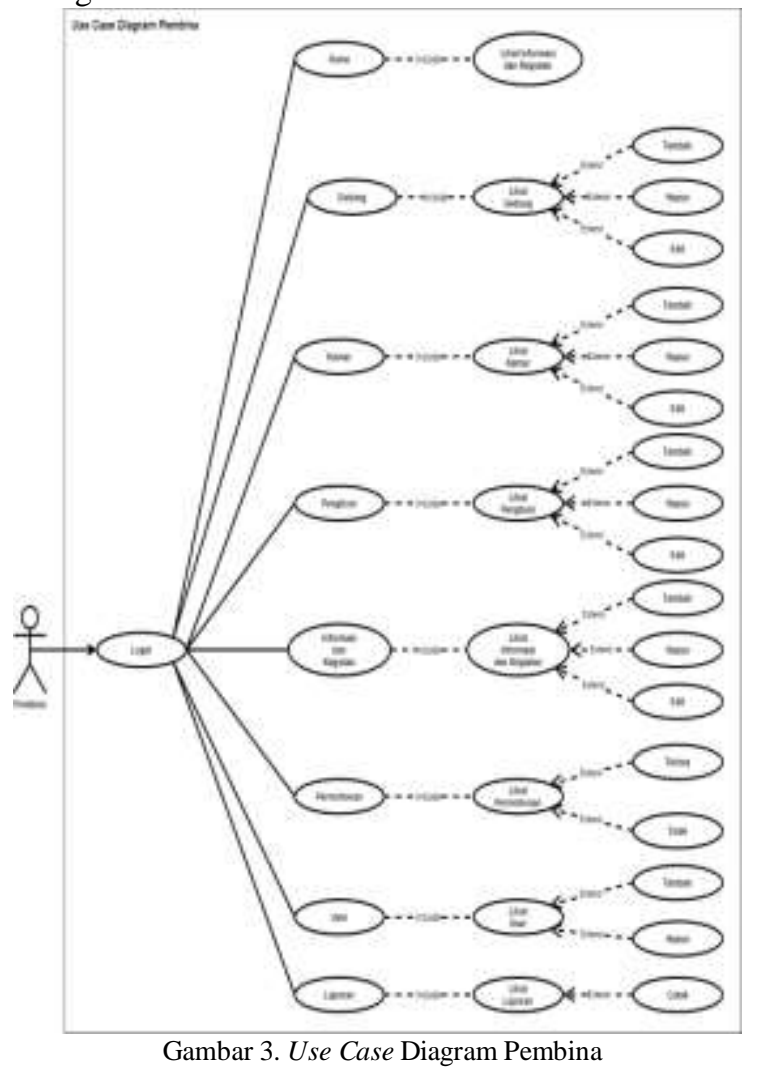


2. Use Case Diagram Pengurus

Adapun desain use case diagram pengurus adalah sebagai berikut :

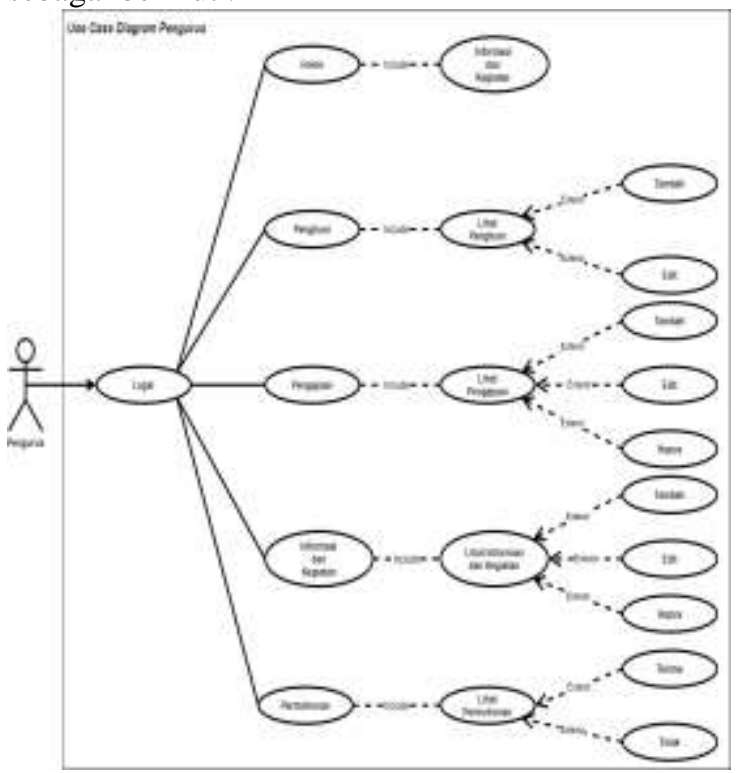

Gambar 4. Use Case Diagram Pengurus

3. Use Case Diagram Penghuni

Adapun desain use case diagram penghuni adalah sebagai berikut :

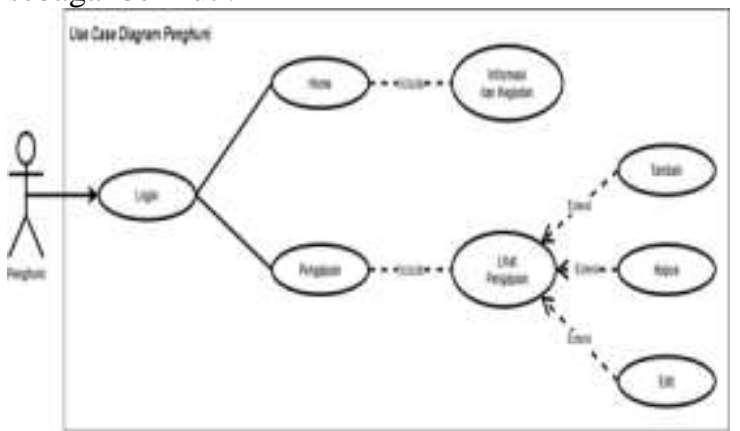

Gambar 5. Use Case Diagram Penghuni

\section{Implementasi Program}

Setelah membuat desain sistem dan desain user interface, peneliti melakukan implementasi sistem dari desain yang telah dibuat. Adapun implementasi dari Sistem Informasi Manajemen Rumah Susun Sumbawa Berbasis Web adalah sebagai berikut :

\section{Tampilan User Interface Login}

Adapun tampilan user interface login adalah sebagai berikut :

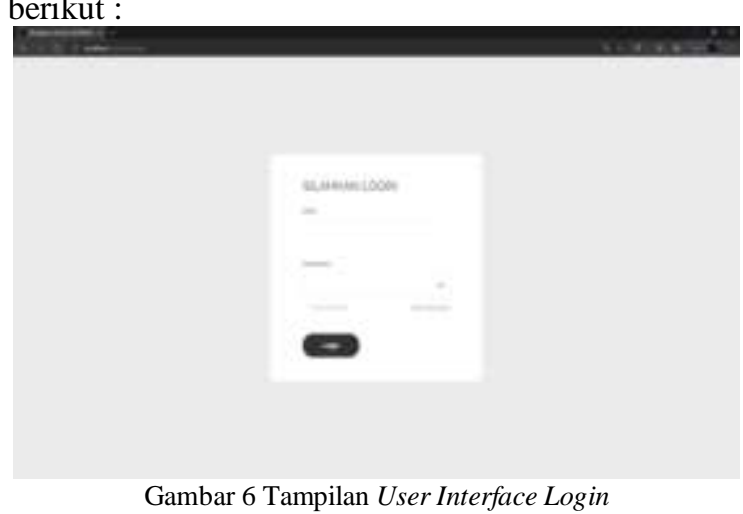

2. Tampilan User Interface Home Pembina Adapun tampilan user interface home Pembina adalah sebagai berikut :

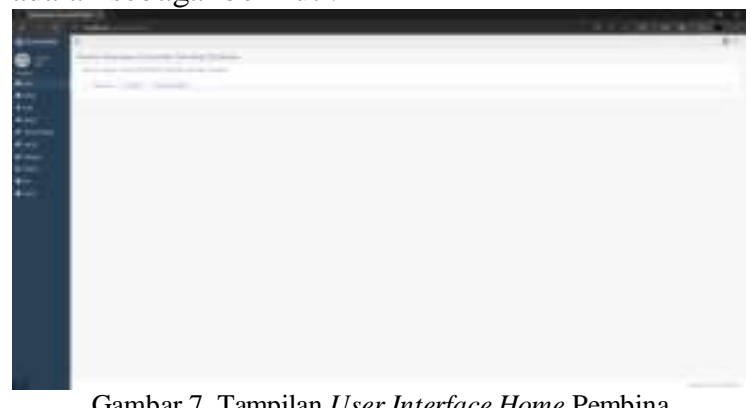

Gambar 7. Tampilan User Interface Home Pembina

3. Tampilan User Interface Informasi dan Kegiatan Oleh Pembina

Adapun tampilan user interface informasi dan kegiatan oleh Pembina adalah sebagai berikut :

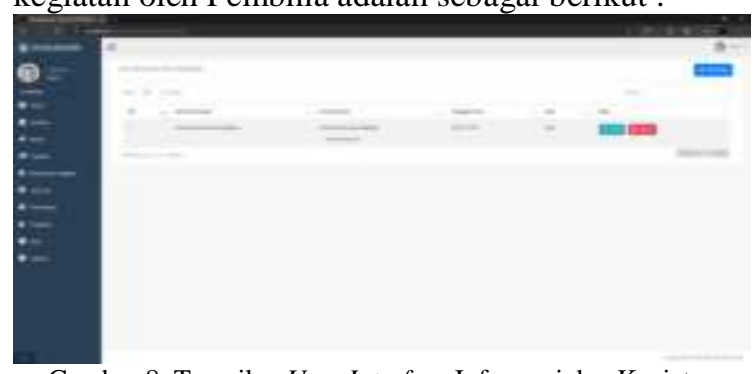

Gambar 8. Tampilan User Interface Informasi dan Kegiatan Oleh Pembina

\section{Tampilan User Interface Tambah Jenis Izin Oleh Pembina}

Adapun tampilan user interface tambah jenis izin oleh Pembina adalah sebagai berikut :

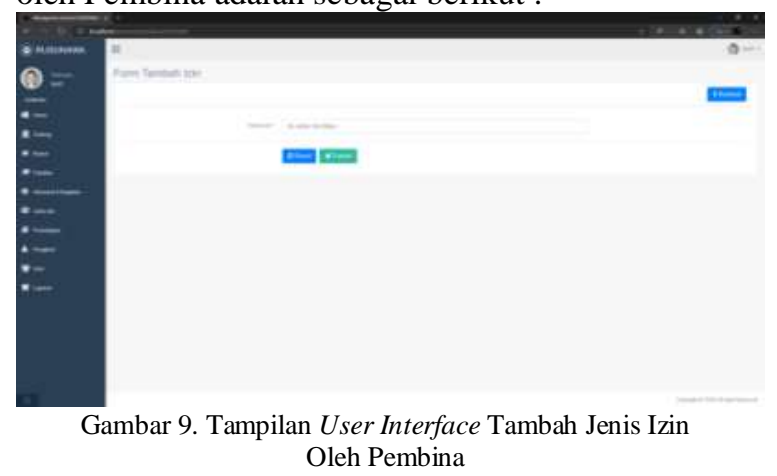

\section{KESIMPULAN DAN SARAN}

Dari hasil hasil analisis dan desain sistem yang telah dikerjakan, maka dapat diambil kesimpulan bahwa Sistem Informasi Manajemen Rumah Susun Sumbawa Universitas Teknologi Sumbawa Berbasis Web telah selesai dibuat menggunakan bahasa pemrograman PHP dan database MySQL menggunakan Waterfall Methode sebagai pengembangan perangkat lunak. Dengan selesainya dibuat Sistem Informasi Manajemen Rumah Susun Sumbawa Berbasis Web maka dapat menjadi masukkan bagi pengelolah RUSUNAWA UTS untuk mempermudah dalam melakukan seluruh kegiatan yang ada di RUSUNAWA, memudahkan dalam melakukan pendataan penghuni dan 
mempermudah dalam melakukan izin di RUSUNAWA.

Dari Sistem Informasi Rumah Susun Sumbawa Universitas Teknologi Sumbawa Berbasis Web, peneliti memberikan saran agar selanjutnya dapat dilakukan pengembangan pada sistem dengan menambahkan fitur baru berbasis sms gateway.

\section{DAFTAR PUSTAKA}

[1] Jogiyanto HM. (2008). "Metodologi Penelitian Sistem Informasi”. Yogyakarta: Andi Yogyakarta.

[2] Pressman, Roger S. (2002). "Rekayasa Perangkat Lunak: Pendekatan Praktisi (Buku 1)”. Yogyakarta: Andi Yogyakarta.

[3] Susanto, R. \& Andriana, D, A. (2010). "Perbandingan Model Waterfall dan Prototyping Untuk Pengembangan Sistem Informasi". Majalah Ilmiah UNIKOM. Vol. 14 No. 1 Hal. 43. Tanggal Akses: 3 Maret 2020.

[4] Pudji, K. \& Endrianto, E. (2012). “Rumah Susun Sewa Mahasiswa Universitas Muhammadiyah Semarang”. IMAJI. Vol. 1 No. 3 Hal. 485. Tanggal Akses: 16 April 2020.

[5] Ropianto, M. (2016). "Pemahaman Penggunaan Unified Modelling Language”. JT - IBSI. Vol. 1 No. 1 Hal. 43. Tanggal Akses: 16 April 2020.

[6] Putra, T, W, D. \& Andriani, R. (2019). "Unified Modelling Language (UML) Dalam Perancangan Sistem Informasi Permohonan Pembayaran Restitusi SPPD”. Jurnal TEKNOIF. Vol. 7 No.1 Hal. 33. Tanggal Akses: 17 April 2020.

[7] Safitri, S, T. \& Supriyadi, D. (2015). "Rancang Bangun Sistem Informasi Praktek Kerja Lapangan Berbasis Web Dengan Metode Waterfall”. Jurnal Infotel. Vol. 7 No. 1 Hal. 70. Tanggal Akses: 17 April 2020.

[8] Nisa, Haerun, Shinta E \& Rodianto. (2017). "Sistem Informasi Kepegawaian Berbasis Web Pada Unit Pelaksana Teknis (UPT) Puskesmas Kecamatan Unter Iwes". Jurnal Tambora. Vol. 2 No. 3. Tanggal Akses: 17 April 2020.

[9] Alfarisyi, I, M. \& Amila, K. (2014). "Rancang Sistem Informasi Layanan Alumni ITENAS Berbasis WEB". Reka Integra. Vol. 2 No. 1 Hal. 134. Tanggal Akses: 16 April 2020.

[10] Priyanti, D. \& Iriani, S. (2013). "Sistem Informasi Data Penduduk Pada Desa Bogoharjo Kecamatan Ngadirojo Kabupaten Pacitan". IJNS. Vol. 2 No. 4 Hal. 56. Tanggal Akses: 4 Maret 2020.

[11] Fahriya, K. \& Nurhidayat, I, A. (2018). "Rancang Bangun SIMAWA (Sistem Informasi Rusunawa) Berbasis WEB Application Menggunakan Framework Laravel (Studi Kasus : Universitas Negeri Surabaya)". Jurnal Manajemen Informatika. Vol. 8 No. 2 Hal. $121-128$ Tanggal Akses: 30 April 2020.

[12] Mufizar, T., Hidayat, R. C. \& Kamaludin, W. (2018). "Sistem Informasi Integrasi Untuk Pengelolaan Rusunawa STMIK Tasikmalaya”. SENSITEK. Tanggal Akses: 2 Mei 2020.

[13] Rosa, A, S. \& Shalahudin, M. (2018). "Rekayasa Perangkat Lunak Terstruktur dan Bererientasi Objek”. Bandung: Informatika.
[14] Rodianto, M. Abduh R \& Nora DS. (2020). "Sistem Informasi Alumni Program Studi Teknik Informatika Universitas Teknologi Sumbawa Berbasis Web”. Jurnal JINTEKS. Vol. 2 No. 1 Hal. 59 - 68. Tanggal Akses: 20 Maret 2020.

[15] Hendini, A. (2016). "Pemodelan UML Informasi Monitoring Penjualan dan Stok Barang (Studi Kasus : Distro Zhezha Pontianak)". Jurnal Khatulistiwa Informatika. Vol. 4 No. 2 Hal. 108 - 110. Tanggal Akses: 10 Maret 2020.

[16] Hariyanto, S. (2016). "Sistem Informasi Manajemen”. Jurnal PUBLICIANA. Vol. 9 No. 1 Hal. 80 - 81. Tanggal Akses: 16 April 2020.

[17] Veronika, N, D, M. \& Darnita, Y. (2015). "Rancang Bangung Aplikasi Tes TOEFL Menggunakan Algoritma Quick Sort Berbasis Komputer". Jurnal Pseudocode. Vol. 2 No. 2 Hal. 89 - 97. Tanggal Akses: 19 Januari 2021. 